\title{
Hackers and Cyborgs
}

\author{
Binary Domain and Two Formative Videogame Technicities \\ Brendan Keogh
}

Transactions of the Digital Games Research Association

2016, Vol. 2, No. 3, pp. 195-220

ISSN 2328-9422

http://todigra.org

TEXT: Licensed under Creative Commons Attribution (CC BY-NC- ND

2.5) http://creativecommons.org/licenses/by-nc- nd/2.5/

IMAGES: All images appearing in this work are property of the respective copyright owners, and are not released into the Creative Commons. The respective owners reserve all rights.

\section{ABSTRACT}

Through the course of Binary Domain's action-packed narrative, it becomes increasingly unclear who is human, who is machine, and who is somewhere in between. Ultimately, such a distinction is futile when our everyday experiences are so ubiquitously augmented by technologies — even the act of playing Binary Domain by coupling with a virtual character through a videogame controller challenges any clear distinction between human and machine. While such themes are not new to science fiction, the anxieties expressed by Binary Domain's characters are relevant to what have emerged over the past twenty- five years as two formative modes of identifying with videogames: the dominant hacker and the integrated cyborg. The hacker, an identity that the dominant and hegemonic 'gamer' consumer identity can trace a clear lineage from, comes to represent the masculinist, mastery-focused identity that most blockbuster games celebrate. The cyborg emerges in resistance to the 
hacker, pointing to a diversity of forms and identities that are focused less on mastering the machine than participating with it. This paper uses Binary Domain's complex anxieties towards technology as a lens through which to trace the histories of these constitutive modes of identifying with videogames, and to demonstrate the influence they have on videogame forms and audiences.

\section{Keywords}

Cyborg, hacker, gamer, Binary Domain, technicity, criticism, feminism, analysis

\section{INTRODUCTION}

After a skirmish with a robot army early in Sega's Binary Domain (2012), Big Bo raises his gun at the slum kids who creep out of the shadows to salvage the scrap metal. "No!” the playable character Dan Marshall warns his companion. “They're human!” Big Bo looks back at the children suspiciously, "And how the hell can you tell that?” Dan is incredulous: "How in the hell can't you?” [1]

What it means to be a 'human' is a notion constantly challenged by the pervasive presence of technology in our everyday lives. Pacemakers, prosthetic limbs, automobiles, GPS, internet connections all mediate and alter existence. For Donna Haraway, late twentieth-century machines challenge a range of conceptual dualisms that have long held dominant sway: "Our machines are disturbingly lively, and we ourselves are frighteningly inert” (1991, p.152). To account for-and to embrace-this rising ambiguity between mind and body, natural and artificial, human and machine, Haraway finds a productive metaphor in the figure of the cyborg, a hybrid of machine and organism. Videogame play in particular is a vivid and explicit performance of the cyborg, as scholars have noted (Lister et al 2009; Dovey and Kennedy 2006; Giddings 2008). To play a videogame is to both expand and constrain bodily ability through technological augmentations (controllers, motion sensors, touchscreens) 
and to both step into and become part of an integrated circuit of human and nonhuman actors (Giddings and Kennedy 2008). However, at the same time, the dominant identities cultivated around the videogame form by marketing and enthusiast press discourses are those of humanist (and masculinist) empowerment, agency, and choice: strong space marines, efficient racing cars, god-like (and god-eyed) strategists. Such dominant understandings of how players engage with videogames see players less as integrated and participatory cyborgs and more as dominant hackers: using the technology to do what they want it to do, to make the choices they want to make, to beat the technology, to win. Yet, with the rise of DIY or 'zinester' games at one end of the game design spectrum (Anthropy 2012) and casual and mobile games at the other (Juul 2010), the core 'gamer' identity that values autonomy and mastery is increasingly contested by newer modes of identifying with videogames that shift the focus back towards more earnestly restrictive engagements concerned with the player's participation rather than their domination. Two formative conceptualizations of the player thus emerge: the player as determining and in charge and 'using' technology, and the player as partially determined by and integrated with technology.

Through the anxieties and tensions between humans and machines expressed by Binary Domain, this article demonstrates how these two modes of identifying with and evaluating videogame forms are fruitfully explored as two formative technicities. By 'technicity' I draw on Tomas's coining of the term in his exploration of William Gibson's Sprawl novels where Tomas forwards technicity to account for the "different systems of identity composition" that emerges in "cyborg-dominated culture” (1989, p.123), and I rely on the work of Dovey and Kennedy (2006) who productively build on Tomas's outline to bring a discussion of technicity directly to videogame culture. Concerns of technicity intersect with concerns of gender, ethnicity, and class to account for how particular social and cultural relationships and power dynamics are formed through technological competency, access, and literacy. Further, technicity provides a way to explore how certain modes of identifying with technology become dominant and hegemonic to obscure a myr- 
iad of other "marginal, subaltern or oppositional identities which define themselves in reference to the dominant group" (Dovey and Kennedy 2006, 64). Videogames, as this article's analysis will demonstrate, privilege the hegemonic power of the 'hacker' technicity that underlines the 'gamer' identity while marginalizing those videogames and their players that value technological engagements beyond the strictly ludic ones of goal-based mastery and challenge. A discussion of these dominant and alternative technicities is particularly relevant at this time. The past five years have seen the emergence of a variety of videogames that conflict with traditional modes of understanding the videogame form, and the past twelve months in particular have seen provoking discussions in popular videogame discourses as to just what videogames 'should' do and who they are made for, as seen in various recent creator manifestos committed to treating the player as less than central (Brice 2014; Polansky 2014; Kopas 2014).

Binary Domain is set in a near-future, post-climate change world where the need for a massive labor pool to rebuild the sunken cities of the world motivates swift advancements in robotic technologies. However, with new technology comes new anxieties. The United Nations passes a New Geneva Convention that inscribes into international law the banning of creating robots that could pass as human. As the game begins, the player's protagonist, Dan Marshall, joins a UN Security Council-sanctioned task-force known as a 'Rust Crew' to infiltrate Japan, returned to isolationism, to investigate a suspected breach of the New Geneva Convention by the Amada Corporation. There is reason to believe that Amada has not only created robots that pass as human, but that these robots themselves are unaware of what they are, living their day-to-day lives unaware that they are, in fact, not 'real' humans. The game plays as a standard third-person shooter, where the player navigates Dan to cover before shooting at advancing robotic armies. The game's narrative, however, unfolds more complexly against this mechanically conventional backbone. It becomes increasingly unclear just who is human and who is machine as suspicion turns to each of Dan's allies and enemies in turn before turning, finally, to the Binary Domain players them- 
selves. Late in the game, after one particularly difficult skirmish, one of Dan's allies mockingly compliments Dan's prowess and asks if he is sure he is not part robot himself. Dan, controlled and augmented by a player wrapped around a videogame controller and facing a television screen, fights so well and is so strong that his squadmate suspects that he may not be a 'real' human. This squadmate, ironically, suggests that the assemblage of flesh and machine that allows the character to perform so admirably (playable character, virtual camera, and a corporeal player entangled with videogame hardware) might be a cyborg.

Through its explorations of the tensions between humanism and posthumanism, Binary Domain aligns itself with a long lineage of science fiction works in a variety of genres. Films like Blade Runner (Scott 1982), Metropolis (Lang 1927), and Bicentennial Man (Columbus 1999); and books like The Windup Girl (Bacigalupi 2009) and Neuromancer (Gibson 1984) all explore the increasingly blurred line between human and technology; or perhaps more accurately, that such a line was only ever a conceptual fantasy. Whereas films and literature can only ask the audience to reflect on how such human-technology hybridizing already functions in their everyday life, the "literally cyborgian" performance of videogame play (Lister et al. 2009, p.306) augments the player's bodily actions with technological hardware and provides a fruitful demonstration of such an indistinction between flesh and machine. Binary Domain thus explores the blurring of identities that videogame play fundamentally depends on. With its characters so determined to keep the purity and essence of a privileged hegemony (humans) distinct from the corrupting influence of the marginalized (hon-humans) despite the insistence of a world where such distinctions have long been impossible, Binary Domain provides a potent lens onto the tensions between dominant (gamer) and marginal videogame technicities.

The first section of this article will trace the lineage of the cultivated 'gamer' identity through a pre-existing hacker mythos to demonstrate how videogames, from the start, became naturalized as masculinist and how this shaped a dominant technicity that persists today. The second 
section will contrast this dominant technicity with those cyborg technicities that emerge through marginal and casual game design. The tensions raised between the two technicities will be explored through Binary Domain's characters' discovery of 'hybrid people': fully organic people with a robotic parent. The hybrid people force a conceptual realigning of just what it means to protect the sanctity of 'Human'-simply being fully organic is no longer enough. As those with power in Binary Domain constantly shift the definition of 'Human' to ensure its purity and deny access to those it wishes to oppress, so too is the 'gamer' identity able to shift definitions and borders to exclude a range of technicities that challenge the hegemonic dominance of the gamer-hacker. The final section, then, will stress that in outlining these two formative technicities, the hacker and the cyborg, it is important to not suggest that they exist hermetically in some dualistic battle, but as complementary perceptions on how humans engage with technology. As the cyborg's integration emerges in reaction to the hacker's dominance, the hacker's dominance is dependent on the cyborg's integration. Less interesting than which technicity is 'right' is how each renders legible particular perspectives on the videogame form for designers, critics, and players alike, and that is what this article aims to accentuate.

\section{THE GAMER AS HACKER}

While Binary Domain sports a more diverse range of characters than many blockbuster games, with the player's six-person squad consisting of four nationalities and two women, the playable character remains the normative videogame trope of the white, heterosexual, American man. Binary Domain also plays with this conventionality, however, as the British character Charles Gregory is technically in command of the Rust Crew while the player's Dan Marshall plays the role of both pigheaded American brute and inevitable hero. As Dan is connected to the player, the experience inevitably centers around his experience of saving the world (and the woman). While Binary Domain delivers Dan's character with its tongue firmly planted in its cheek, he remains typi- 
cal of a broader videogame status quo. The overwhelming representation of male and white characters as playable characters in industrially-produced videogames is well-documented and well-critiqued by a range of critics (Anthropy 2012b; Sarkeesian 2013; Dovey and Kennedy 2006; Walker 2013; Conditt 2015). Through these characters saving the world through physical prowess, a target audience of young, white men are empowered and catered to while other demographics become secondary. Such a dominant form of character that becomes the dominant mode of engaging with videogames does not come from nowhere, but exists within an ongoing trajectory of dominant masculine technicities. Here, it is important to see how the 'gamer' as the normative male videogame player in charge of characters like Dan exists and is cultivated by a constructed consumer identity that demands and values a certain, hackerinfluenced technicity.

The 'gamer' persists as the dominant videogame player identity, often problematically used in both popular and scholarly discourse as a synonym for 'videogame player'. That the 'gamer' is often titled more specifically the 'core gamer' points to the conceptual centricity of this identity as the most important identity to videogame culture. However, as researchers such as Shaw (2011) and Kirkpatrick (2012) have shown, only a very particular subset of videogame players consider themselves to be gamers. Further, a 2015 national survey by Australia's Interactive Games \& Entertainment Association (IGEA) found that only 38\% of those surveyed consider the term 'gamer' to simply mean 'someone who plays videogames'. Rather, for most people, 'gamer' refers to those videogame players that commit much time and money to those most 'authentic' videogame experiences: expensive, high fidelity, highly challenging blockbuster experiences - the games that demand a complicated, dexterous virtuosity, and the dozens of hours of free time in order to develop such a skill. Such games that a core gamer culture privileges perpetuate a dominantly masculine culture with narratives and actions focused on men achieving goals and exerting power through physical feats, with entrenched themes of militarism and mastery (Wajcman 1991, 154; Anthropy 2012b, 12). These blockbuster games typically and nor- 
matively position the player as 'in charge' and possessing a personal and autonomous responsibility, as is most explicit in the language used to address gamers on the back covers of any blockbuster game: "The choices you make will shape your fate and that of the empire around you," insists the cover of Dishonored (Arkane 2012); "You choose from 120 events. You choose the fasted route to the finish line. You shape your path through Paradise [City]," boasts the cover of Burnout Paradise (Criterion 2008); "Every action has consequence and could decide whether the crowd will help you... or hinder you!" threatens the cover of Assassin's Creed (Ubisoft 2007). Blockbuster videogames have long been sold to a cultivated target audience through promises of freedom and autonomy: the choice is yours! Through such presumptions to autonomy and freedom and control, the virtuosic quickly becomes the most authentic performance: how well the gamer did, how good their decisions were, how accomplished they are at playing-and at defeating - the game. To play the game is to beat the game (or die trying).

The 'gamer' continues an existing trajectory of dominant masculine identities inscribed onto technology use through the twentieth century. Here, it is revealing to link the gamer identity as it emerges in the 1980s and 1990s to the romantic notion of the hacker mythos through the 1960s and 1970s. Truly, it is impossible not to make such a link. While others have made constructive links between early videogame design and new media forms of the late 19th and early 20th century such as the penny arcades, nickelodeons, and panoramas (Huhtamo 2005; Golding 2014), videogames as a form emerge explicitly from American university hacker culture. Spacewar! (Russell et al 1962), arguably the first videogame, was produced by students hacking and appropriating a PDP-1 at MIT. Since then, the symbiosis of videogame and hacker cultures is well documented, from the origins of early commercial videogames being produced by engineers and software students (Donovan 2010), to game magazines that rather than supplying discs, present pages of code for the young gamer/hacker to type into their own computer at home (Kirkpatrick 2012), to more contemporary modding cultures (Dyer-Witheford and de Peuter 2009, p.185). The hacker in their 
(usually his) bedroom, creating the next million dollar software company or game studio is a frontier narrative for the twentieth century.

However, this mythos of nerds building up technology in campus dorm rooms and garages, picking themselves up by their own bootstraps, also re-inscribes a dominant masculinity, as feminist scholars of technology have traced. In particular the work of Sherry Turkle (2005 [1984]) and Judy Wajcman (1991) is significant. Turkle’s ethnographic research on the hacker culture of MIT's campus through the 1980s reveals a culture that is masculinist and hostile to women (2005, p.194), that focuses on "playing with" computers rather than using them (2005, p.193-194), that appreciates formal complexity for its own sake (2005, p.197), and which views complex systems as something that must be defeated in contest (2005, p.197). Turkle's hackers are playful in a strictly ludic, goal-orientated sense: the computer offers a problem to be solved. Tellingly, when Turkle expresses to one of her interviewees that she wants to understand the 'feel' of hacking, the hacker suggests she plays the videogame (contemporary at the time of the interview) Adventure. Adventure, Turkle found, captured the hacker experience of "living with his code" much better than a simple computer programming course: "It is the introductory computer course that fails to give its students a sense of what programming is to its virtuosi. When systems get complex they become worlds that you can live in” (p.2005, 206). While videogames do not require the same programming literacy or virtuosity as does hacking complex computer systems, they commonly value similar experiences of understanding and mastering complex systems and, ultimately, bringing them under control.

Wajcman builds on and critiques Turkle's work to contextualize the hacker identity within broader cultural factors such as race, class, gender, and age in a significant precursor to this paper's concern with technicity. Wajcman notes that while the individuals that make up hacker collectives commonly self-identify as losers or loners, these "mainly white middleclass men" draw "on the culturally dominant form of masculinity for their notions of risk, danger and virility in their work” (1991, p.144). 
Wajcman highlights the "complex relationship between knowledge, power and technology” (1991, p.144) that is pointed to through how the men in these hacker groups both lack and possess power through their technical expertise: many hackers are marginalized from cliché understandings of masculinity built on physical prowess, but also possess particular cultural and societal privileges through their technical prowess. Significantly, Wajcman is critical of Turkle's tendency towards gender essentialism $(1991,157)$, instead situating masculine approaches to technology through the historically unequal access to computers between genders. While computing originates as a woman's domain when 'computers' were human (Hayles 2005, 1), they were masculinized as they became machines linked with military bases and the scientific and mathematical faculties of schools and universities. The pre-existing gender disparity in educational departments is thus reinscribed through access to computers (Wajcman 1991, 152). Of course, Wajcman was writing several decades ago, but the history remains relevant: computer use (and by extension, videogame play) was long naturalized as masculine, was the realm of the engineer and the mathematician, and inherited and perpetuated Western and neoliberal masculine values of control, mastery, and autonomy, as most clearly seen through the mythos and aesthetics of the hacker. Significantly, while Turkle is celebratory of her ability to comprehend the pleasures of hacking through early videogames, Wajcman's explicit link between videogames, hacker culture, and dominant masculinities is more critical:

\footnotetext{
"Games are the primary attraction of computers for children. Given that it is men (often computer hackers) who design video games and software, it is hardly surprising that their designs typically appeal to male fantasies... Many of the most popular games today are simply programmed versions of traditionally male non-computer games, involving shooting, blowing up, speeding, or zapping in some way or another. They often have militaristic titles such as 'Destroy All Subs' and 'Space Wars', highlighting their themes of adventure and violence. No wonder then that these games often frustrate or bore the non-macho players exposed to them." (Wajcman 1991, p.154)
}

While videogames today encompass a far broader diversity of genres 
and forms of attention, that Wajcman's observations of the state of the videogame form could still be said today about the most dominant videogame works produced by the industry (Binary Domain included) points directly to the lingering legacy of the 20th Century hacker and its masculinist normativity on gamer culture and production, on what is valued and by who.

Such ubiquitous masculinities do not only determine which videogames are more likely to be created, but which videogames are valued as exemplary of the form. Directly descendant from the hacker cultures of the previous decades, those games made for gamers through the close of the 20th Century and into the 21st that are most valued by videogame critics are those that allow the player to express a sense of freedom, agency, autonomy, power, and control: players take on powerful roles like commander, mayor, god, soldier, gangster, or superhero to both save the world and, more often than not, save the girl. Critical discourses surrounding videogames have been quick to embrace these values as seemingly inherent to the videogame form rather than socially constructed through its most dominant works. Kirkpatrick traces the etymology of 'gameplay' as an essence that is meant to distinguish videogames as a unique cultural practice but which instead comes to signify "the tastes and preferences of the authentic gamer” (Kirkpatrick 2012). Scholarly discourses on videogames, too, unproblematically inherit many of the normative values of a hacker mythos when evaluating the videogame form. The focus on player agency that potentially prevents videogames being evaluated as texts (Aarseth 2004, p.47), the celebratory tone often invoked when discussing corporate technological advances (Keogh 2014), user-generated content such as mods as somehow more liberating than conventional videogame play (Banks and Humphreys 2008) all depend on and play into an understanding and evaluation of videogames specifically and technology broadly that runs parallel with a hacker technicity. This is often explicitly gendered, too, such as Aarseth's (2004) comment that what Lara Croft's body in Tomb Raider looks like matters far less than what he can do with it, privileging the agency and actions of the player in a computational system over the gendered representational 
strategies of the videogame. Just as the hacker is concerned with mastering complicated systems and ultimately beating the form of the computer, so too is the gamer concerned with mastering complicated systems of mechanics and ultimately beating the form of the videogame. Writing in 2002 to defend the oft-dismissed videogame cut-scene, Klevjer explicitly claims ludology to be "partly rooted in the dark arcade of the late 70s and early 80s, partly rooted in hacker culture” (p.193). That the study of videogames in many institutions still finds an uneasy (though at time constructive) home between the humanities and computer engineering departments points towards the everydayness of these tensions.

As a consequence of its historical construction as masculine and its alignment with the hacker technicity that favors a particular technological competency, mechanistic virtuosity, and systems literacy, discourses around videogames (both scholarly and popular) have produced what Dovey and Kennedy note is "an 'ideal' player subject that is naturalized as 'white', 'male' and 'heterosexual'” (2006, 63). Similarly, Shaw's survey exploring just who self-identifies as a 'gamer' confirms that "male interviewees were much more likely to identify as gamers than female, transgender or genderqueer interviewees were” (2011, 34) and that such self-identification has little to do with whether or not the interviewees played videogames, or for how long. In other words, many non-male videogame players, even if they play videogames frequently, do not consider themselves to be 'real' gamers or the games that they play to be 'real' games. Dominant understandings of videogame play, taking masculinist ideologies as inherent values, obscure the heterogeneous spectrum of meaningful and significant experiences players have with videogames to instead allow a highly gendered, formalist, and conservative conceptualization of videogame play to dominate. The hacker technicity of videogame play thus points to the dominant, normative, hegemonic, and masculine; it points to that audience with the most power, and speaks to their values while inevitably marginalizing and obscuring a plethora of other identities and values that surround videogame play but which are delegitimized by a dominant discourse. 


\section{THE PLAYER AS CYBORG}

Whereas Dan is an archetypical white, heterosexual, macho American male, his fellow Rust Crew squadmate Faye Lee is a stereotypical, quiet, and slim heterosexual woman from rural China-_Farm Girl”, Dan playfully (and mockingly) calls her through the opening chapters of the game. Faye, at first, treats Dan with contempt, but in a typical masculine narrative fashion, Dan's (and thus the player's) strength and physical ability wins Faye over and soon they fall for each other. This is complicated by a reveal towards the end of the game: not that Faye is a robot (a reveal that both Dan and the player come to expect) but, rather, that she is what Binary Domain calls a 'hybrid person'. Female androids produced by the Amada Corporation who themselves did not realize they were robots fell pregnant to human males and had human children, of which Faye is one. Faye, despite being completely organic in composition, is a literalisation of Haraway's “illegitimate offspring” of flesh and machine (1991, p.151), and Faye's very existence is a breach of the New Geneva Convention. The sheer lack of empathy in the voices of Charles Gregory and the other members of the Rust Crew towards their squadmate when her ancestry is revealed is shocking; despite the fact she meets a strictly biological definition of what it means to be human, they no longer conceive of her as human and thus she must be terminated. The critique that Binary Domain is able to make with the late reveal of the existence of hybrid people is a level above that made by works with an android who becomes human (or vice versa) over time. Rather than a transition from one stable category (non-human) to another (human), the reaction of the characters to the hybrid people reveals how biological understandings of what it means to be a 'human being' have little influence of what it means to be socially constructed and accepted as 'Human'- . The hybrid people suggest, further, that despite being constituted solely by organic material, you may also be, simultaneously, a product of flesh and machine—an everyday cyborg.

The exclusionary practices of the category of 'Human' have been well documented by scholars. Foucault shows how the concept of 'Man' is 
one only a few centuries old, tracing it back to the Western Enlightenment (2005 [1966]). Latour's work shows how 'Human' is defined through a split between nonhuman Nature and human Culture in such a way as to ensure Man's dominion of both (1991). Most significantly for this article, Hayles demonstrates how the liberal, Enlightenment concept of 'Man' as autonomous and possessing agency and free will over His own life is a conception that "may have applied, at best, to the fraction of humanity who had the wealth, power, and leisure to conceptualize themselves as autonomous beings exercising their will through individual agency and choice” (1999, p.286). The dualistic tendencies of modernist approaches to conceiving what it means to be human is responsible for a range of pervasive ontological dichotomies such as man/woman, man/world, nature/culture, man/ god, form/content, mind/ body. These dualisms find their way into conceptions of technology and computer use through the hacker mythos, itself a continuation of this liberal, Enlightenment Man mastering and exerting control over His (technological) world. It is this same conception of human, defined by and depended on by those possessing and consolidating power that ensures Faye is excluded from the human race through her ancestry. 'Human' is thus exposed as a hegemonic identity defined by what it excludes, and shifting its definition to ensure those excluded remain excluded.

Feminist technology and cyberculture studies have traced these links in far more detail than this paper has the scope to reiterate (Haraway 1991; Hayles 1999; Casper 1994; Wajcman 1991), but the point remains: if the hacker is a hegemonic and dominant technicity in both technology culture broadly and videogames specifically, it is so as a continuation of those hegemonic and dominant identities that have been naturalized as male and white for centuries. The cyborg emerges as a response to these identities, embracing the hybridity, impurity, and ultimate partiality that destabilize their hegemonic dominance. For Haraway in particular, the cyborg is an explicitly feminist metaphor that contests not just dominant knowledges, but dominant ways of knowing:

"Perhaps, ironically, we can learn from our fusions with animals and 
machines how not to be Man, the embodiment of Western logos. From the point of view of pleasure in these potent and taboo fusions, made inevitable by the social relations of science and technology, there might indeed be a feminist science.” (1991, p.173)

Where the hacker strives for autonomy and dominance over the machine, the cyborg embraces the fact it is always already in part shaped and mediated by the machines it integrates with.

As Dovey and Kennedy note in their own exploration of the gendering of videogame culture through the hacker mythos, "If a particular group is dominant then we can be sure that there are other stories, identities and creative processes that get written out of the discourse of dominance” (2006, p.76). Much of early videogame studies, for instance, stresses as essential to the form the ability of the player to freely 'act', to exert agency over the game. Indeed, the early debates between narrative and play circled around such a notion that a more active audience would be more free of the author's control than the film viewer or book reader. Such an understanding, however, takes as inherent those values in videogame marketing and design that are simply a dominant norm and have long held up a subset of videogames that focus on mastery, player agency, control, and skill as exemplary of a broader form. In videogame journalism, too, a persistent privileging of more 'open' games over those videogames seen as too linear or tightly authored echoes this conceptual border policing. For instance, consider this review of the game Dear Esther (The Chinese Room 2012):

“Dear Esther is not your traditional concept of a game [...] There's little actual gameplay to speak of: you move about with the arrow keys in firstperson, and that's pretty much it. There are no enemies, no puzzles, nor any items or objects to interact with. You cannot jump, or sprint, and the game will automatically crouch for you if need be. You have a flashlight, but the game will turn it on and off for you. These automatic actions drive home the feeling that you're not even really in control of your character-you're more of an observer inhabiting their headspace. There is one walking pace, and it's deliberately ponderous so that you might take time to appreciate the environment around you because that's really all there is to do." (Hindes 2012, p.48) 
Instead of comprehending what particular engagements Dear Esther offers, the reviewer can only list those formal elements not present in the game. The review suggests that Dear Esther is a game of poor quality because it lacks the typical challenges of dexterity and intellect to be mastered-you are not even "really in control" of your character. When the reviewer says there is "little actual gameplay," they are taking one narrow (yet dominant) conceptualization of videogame play and allowing it to stand in for the myriad engagements possible with videogames. Similarly, a demonstrative user review of the game Gone Home (Fullbright 2013) on review amalgamation site Metacritic complains that “The only semblance of gameplay Gone Home has to offer is 90 minutes of pitiful, painfully easy exploration... To call this a video game is insulting!” Here, Gone Home is not simply a game of poor value due to its lack of normative qualities, but a danger to the very concept of 'Videogame'.

Dear Esther and Gone Home are exemplary of nascent modes of videogame design that do not offer the pleasure of mastery and control that the hacker technicity privileges. Rather, they offer little more than a path to walk down or an environment to explore. There is a distinct lack of anything to 'do' in such games, a lack of explicit choices to be made beyond the navigational. Instead, the pleasures of Dear Esther, Gone Home, and many other videogames is textual and phenomenological, and requires a more integrated and cooperative relationship between the human and the computer-they require cyborgs willing to integrate with the machine, not hackers determined to master it.

Importantly, the videogames least capable of being evaluated by a hegemonic, dominant hacker technicity are those videogames that most explicitly react against the masculinist dominance of the commercial videogame industry. The last decade has seen the rise in both casual mobile games with popular appeal to demographics beyond a core 'gamer' consumer base (Juul 2010; Hjorth and Richardson 2009) as well as vibrant avant-garde scenes of marginal artists, and each has been forced to confront a dominant understanding of videogames that struggles to appreciate such 'non-core' experiences. Casual games, such as 
Candy Crush Saga (King 2012) or Kim Kardashian: Hollywood (Glu 2014) have their overwhelming commercial success trivialized by critiques of how easy they are to play, and the seemingly superficiality of their fiction-as though a woman networking in Hollywood is more superficial than a hulking space marine saving the earth. At the same time, an avant- garde of 'zinester' (Anthropy 2012b) developers emerges - many of whom are women, queer, persons of color, and/or transgender-and the critically acclaimed videogames they have created challenge dominant understandings of the videogame form. As Allen (2013) notes in a comparative piece on how movement is conceived by the open-world and critically acclaimed blockbuster Skyrim (Bethesda 2011) and Anna Anthropy’s autobiographical Dys4ia (Anthropy 2012a), the freedom of movement taken for granted by players in many blockbuster games closely parallels the freedom of social movement possessed by the predominately white, straight, and male creators of those games. Games by queer developers on the other hand, commonly communicate through a lack of freedom of movement, such as the various constraints placed on the player in games such as Dys4ia, Lim (Kopas 2012), or Mainichi (Brice 2012). These restrictions, however, along with the lack of technological spectacle consequential to such games being made beyond the advanced resources available to a large studio, commonly mean that such games find themselves dismissed as less than legitimate games, possessing a lack of things for the player to 'do'. This is perhaps most relevant of all to the renaissance of interactive fiction games seen through the development software Twine (Hudson 2015).

Just as those with the most power in a hegemonic society consolidate their power through constantly renegotiating what it means to be socially legitimized as 'human', the most powerful stakeholders of videogame culture - those that have long taken the values of the hacker mythos as 'natural' to the videogame form rather than dominant — consolidate their power through a negation of those games that directly challenge such narrow definitions. This is perhaps most visible every time a games journalism outlet reports on an industrial survey which shows that half or more videogame players are women. Without fail, a reader will attempt 
to negate such a claim by noting that the games most women play are not 'real' games. Those videogame that focus less on mastery and control, and more on participation and integration are both more accessible and attractive to a broader range of people than the young white men targeted by blockbuster games; simultaneously, are marginalized as less legitimate by the dominant discourses around videogames. Just as Binary Domain's hybrid people are dismissed by those with power moving the goalposts of what it means to be human, the vast majority of hybrid players - cyborg players - are dismissed by a constant consolidation of just what is considered a legitimate videogame in the first place. Acknowledging the rhetorical and evaluative strategies used to make such a move is crucial to allowing a critical discussion of the videogame form to move beyond and react against its most normative instantiations.

\section{DOMINATION THROUGH INTEGRATION THROUGH DOMINATION}

It's useful now to return to the scene late in Binary Domain, mentioned in the introduction of this paper, where the synthesized physical prowess and ability to kill lots of robots by Dan-and-the-player is treated as an opportunity for Dan's squadmates to question his humanity. Dan, as the archetypical macho white male character that personifies the dominant masculinity of the hacker technicity, is here suspected as being too powerful to be a human. Here, the anxiety is not of the cyborg as less than human but of the cyborg as more than human, as too perfect, as possessing more power. Both the instances of Faye as an organic cyborg and Dan as a too-perfect human crucially complicate what this paper has up to now risked presenting as too straightforward a dichotomy. The hacker and the cyborg, as ontological metaphors for understanding the formative identities that mediate videogame culture, do not exist as distinct from one another but as entangled with and constantly reacting against each other. The domination and mastery of the hacker requires machinelike ability, while the cyborg exists, has always existed, in a direct relationship to the hacker from its inception. 
Dovey and Kennedy, in their own discussion of the hacker mythos and dominant videogame technicities, point towards this intricacy, where the "lone individual genius" hacker is often described as having "machinelike minds and inhuman propensities” (2006, p.69). In particular, Dovey and Kennedy look at Kushner's boasting in Masters of Doom (2003) that game developer John Romero could play Pac-man with his eyes closed. Whereas Kushner presents this anecdote as an example of Romero's mastery of the computer, Dovey and Kennedy offer an alternative reading, where the machine has fully trained Romero to respond in the optimal manner. Similarly, speedrunning cultures, that work to use exploits and hacks to finish a game as quickly as possible, are almost computerlike in their split-second inputting of exact button presses. The best hackers, it seems, are cyborgs. While Binary Domain comments explicitly, if flippantly, on the complex overlap between hackers and cyborgs, it is seen less explicitly in a range of blockbuster videogames that use the metaphor of cyborgism to explain the playable character's improbable and exceptional physical strength and dominance in the world. Master Chief, the playable character of Halo (Bungie 2001), is explained to be a biologically-engineered supersoldier, augmented further with alientechnology armor and recharging shields. Other examples are numerous: Assassin's Creed uses a framing device of a character connected to a machine enacting another character to explain their powerful abilities; the playable character of Bioshock (2K Boston 2007) augments their body with powerful potions; Metal Gear Solid's (Konami 1998) Solid Snake is an engineered supersoldier, augmented by nanomachines. In Deus Ex: Human Revolution (Eidos 2011), a game explicitly concerned with technological augmentation, the hardest difficulty setting the player can choose is explained as being for players who are "one with the machine.” Such cyborgism is not limited to science-fiction worlds, either. The playable characters of contemporary military shooters such as Call of Duty: Modern Warfare (Infinity Ward 2007) are augmented with unmanned drones, night-vision, and laser-sights; the undead ranger of Middle-Earth: Shadow of Mordor (Monolith 2014) is augmented by an elven wraith. Across all these stories, actual and virtual, is the implicit 
or explicit suggestion that the human's domination is always dependent on the human's integration with nonhuman technologies.

Indeed, such a point is where the cyborg first enters critical discourse through Haraway as "an ironic dream of a common language for women in the integrated circuit” (1991, p.149). The important point is not that posthuman cyborgs are a hybrid of machine and organism unlike human hackers, but that the dualisms that allow the human to be seen as distinct from the machine-Nature distinct from Culture, Man distinct from Woman, Occidental distinct from Oriental, gamer distinct from nongamer-are themselves constructed illusions and that no such distinction truly exists. Instead, focusing on the inherent cyborgism of videogame play, where human players are seen to be integrated with, rather than strictly dominating the machine, provides fruitful ground to explore broader capabilities of the videogame form, along with more nuanced ways of comprehending them. It puts back into play the corporeality of videogame engagement that is commonly ignored, such as when Galloway claims that "no gameplay is actually happening" at the moment the player stands on a virtual street corner to watch the sunset (2006, p.10). It allows an appreciation for those games and critical manifestos from recent years that work to explicitly de-center the concerns of the player in videogame design, understanding the player more as one element in a much larger circuit rather than as looming over and comprehending a system. It allows for understandings such as Golding's (2013) that see the player as navigating from within, rather than configuring from above, not unlike Haraway's feminist objectivity that insists we always see from somewhere (1988, p.882).

\section{CONCLUSION}

In Binary Domain's most harrowing scene, a man is injured in an explosion, and the injury to his face reveals his metallic skeleton. The man, however, remains unaware that he is a robot, and is confused as to why people are moving away from him in fear. When he sees himself in the reflection of a man's sunglasses, he refuses the truth he sees. 'I'm 
human!” he screams at the people around him, while the visual shot of his synthetic eyeball in a metal skull tells us different. The man's insistence that he is human, in the face of undeniable evidence that his very being is determined by an integration of flesh and machine, while Faye as a fully organic hybrid person is told that she is not human, points towards how 'human' is a socially constructed concept with fluid but constantly policed borders. A microcosm of this broader societal issue is videogames and their gamers, themselves socially constructed concepts with fluid borders that are constantly moving to consolidate the power of the dominant. This paper, using Binary Domain's particular commentary on cyborgism and videogame play within the dominant hacker technicity of the blockbuster space, points towards the foundational tensions between these two formative technicities. It makes no argument for either as 'wrong' or less accurate, but instead insists on the importance of comprehending the influence of each on how different groups of developers, critics, and players evaluate videogame attributes. Understanding videogame technicities as influenced by the hacker in the dominant space, with its masculinist norms of mastery, dominance, and technological and physical prowess; and the cyborg on the other hand with its fundamental partiality and integration with nonhumans better allows us to comprehend a range of contradicting values and arguments made of videogames both scholarly and in popular discourses. It reacts against prescriptive notions of what a videogame ideally should be to instead allow a descriptive appreciation of the various different things that videogames are.

\section{BIBLIOGRAPHY}

2K Boston. Bioshock. 2K Games, 2007.

Aarseth, E. "Genre Trouble: Narrativism and the Art of Simulation.” In First Person: New Media as Story, Performance, and Game, edited by N. Wardrip- Fruin and P. Harrigan, pp.45-55. Cambridge: MIT Press, 2004.

Allen, S. “Trans Movement: Freedom and Constraint in Queer and Open 


\section{ToDiGRA}

World Games.” The Border House, February 4, 2013. http://borderhouseblog.com/? p=10113

Anthropy, A. Dys4ia. Newgrounds, 2012a.

Anthropy, A. Rise of the Videogame Zinesters: How Freaks, Normals, Amateurs, Artists, Dreamers, Dropouts, Queers, Housewives, and People Like You are Taking Back an Art Form. New York: Seven Stories Press, 2012b.

Arkane Studios. Dishonored. Bethesda Softworks, 2012.

Banks, J., and S. Humphreys. "The Labour of User Co-Creators: Emergent Social Network Markets?” Convergence 14, no. 2(2008): 401-18.

Bacigalupi, P. The Windup Girl. San Francisco: Night Shade Books, 2009.

Bethesda Game Studios. The Elder Scrolls V: Skyrim. Bethesda Softworks, 2011.

Brice, M. Mainichi. M. Brice, 2009.

Brice, M. “Queer as in Fuck Me - A Design Manifesto.” Alternate Ending, November 18, 2014. http://www.mattiebrice.com/queer-as-in-fuckme-a-design- manifesto/

Bungie. Halo: Combat Evolved. Microsoft, 2001.

Casper, M J. "Reframing and Grounding Nonhuman Agency: What Makes a Fetus an Agent?” American Behavioral Scientist 37, 1994: 839-56.

Columbus, C. Bicentennial Man. Touchstone Pictures, 1999.

Conditt, J. "Gaming While Black: Casual Racism to Cautious Optimism.” Joystiq, 16 January, 2015. http://www.joystiq.com/2015/01/16/ gaming-while-black- casual-racism-to-cautious-optimism/ 
Criterion Games. Burnout Paradise. Electronic Arts, 2008.

Donovan, T. Replay: The History of Video Games. East Sussex: Yellow Ant, 2010.

Dovey, J., and H. Kennedy. Game Cultures: Computer Games as New Media. Berkshire: Open University Press, 2006.

Dyer-Witheford, N., and G. de Peuter. Games of Empire: Global Capitalism and Video Games. Minneapolis: University of Minnesota Press, 2009.

Eidos Montreal. Deus Ex: Human Revolution. Square Enix, 2011.

Foucault, M. The Order of Things: An Archeology of the Human Sciences. New York: Routledge, 2005.

Fullbright. Gone Home. Fullbright, 2013.

Galloway, A R. Gaming: Essays on Algorithmic Culture. Minneapolis: University of Minnesota Press, 2006.

Gibson, W. Neuromancer. New York: Ace, 1984.

Giddings, S., and H. Kennedy. "Little Jesuses and Fuck-Off Robots: On Aesthetics, Cybernetics and Not Being Very Good at Lego Star Wars.” In The Pleasures of Computer Gaming: Essays on Cultural History, Theory and Aesthetics, edited by M. Swalwell and J. Wilson, pp.13-32. Jefferson NC: McFarland, 2008.

Giddings, S. "Playing With Nonhumans: Digital Games as Technocultural Form.” In Worlds in Play: International Perspectives on Digital Games Research, edited by Suzanne De Castell and Jennifer Jenson, pp.115-28. New York: Peter Lang, 2007.

Glu Games. Kim Kardashian Hollywood. Glu Games, 2014.

Golding, D. “To Configure or to Navigate? On Textual Frames.” In 
Terms of Play: Essays on Words That Matter in Videogame Theory, edited by Z. Waggoner, pp.28-46. Jefferson NC: McFarland, 2013.

Golding, D. "Moving Through Space and Time: A Genealogy of Videogame Space.” PhD Diss. University of Melbourne, 2014.

Haraway, D. "Situated Knowledges: The Science Question in Feminism and the Privilege of Partial Perspective." Feminist Studies 14, no.3(1988): 575-99.

Haraway, D. Simians, Cyborgs and Women: The Reinvention of Nature. New York: Routledge, 1991.

Hayles, N K. How We Became Posthuman: Virtual Bodies in Cybernetics, Literature, and Informatics. Chicago: U of Chicago Press, 1999.

Hayles, N K. My Mother Was a Computer: Digital Subjects and Literary Texts. Chicago: University of Chicago Press, 2005.

Hindes, D. “Dear Esther Review.” PC Powerplay March, 2012.

Hjorth, L., and I. Richardson. "The Waiting Game: Complicating Notions of (Tele)presence and Gendered Distraction in Casual Mobile Gaming.” Australian Journal of Communication 36, no. 1(2009): 23-35.

Hudson, L. "Twine: The Program That's Democratised The Video Gaming World.” The Guardian, 11 January, 2015. http://www.theguardian.com/technology/ 2015/jan/11/twine-program-democratisedgaming-world

Huhtamo, E. "Slots of Fun, Slots of Trouble: An Archeology of Arcade Gaming.” In Handbook of Computer Game Studies, edited by J. Raessens and J. Goldstein. Cambridge: MIT Press, 2005..

Infinity Ward. Call of Duty 4: Modern Warfare. Activision, 2007. 
Keogh, B. "Across Worlds and Bodies: Criticism in the Age of Video Games.” Journal of Games Criticism 1, no. 1(2014).

King. Candy Crush Saga. King, 2012.

Kirkpatrick, G. “Constitutive Tensions of Gaming’s Field: UK Gaming Magazines and the Formation of Gaming Culture 1981-1995.” Game Studies 12, no.1(2012).

Klevjer, R. "In Defense of Cutscenes.” In Computer Game and Digital Cultures Conference Proceedings, edited by F. Mayra, pp. 191-202. Tampere: Tampere University Press, 2002.

Konami. Metal Gear Solid. Konami, 1998.

Kopas, M. Lim. Merritt Kopas, 2012.

k, m. Dreaming Digital Play, 2015. http://dreamingdigitalplay.tumblr.com/

Kushner, D. Masters of Doom. New York: Random House, 2003.

Lang, F. Metropolis. Paramount Pictures, 1927.

Latour, B. We Have Never Been Modern. Cambridge: Harvard University Press, 1991.

Lister, M., J. Dovey, S. Giddings, I. Grant, and K. Kelly. New Media: A Critical Introduction. New York: Routledge, 2009.

Monolith Productions. Middle-Earth: Shadow of Mordor. Warner Bros. Interactive, 2014.

Polansky, L. "The Customer is Often Wrong (Fuck the Player).” Sufficiently Human, December 30, 2014. http://sufficientlyhuman.com/ archives/599

Russell, S. Spacewar! Steve Russell, 1962. 
220 ToDiGRA

Sarkeesian. A. "Damsel in Distress: Part 1 - Tropes vs Women in Video Games.” Youtube, March 7, 2013. https://www.youtube.com/ watch?v=X6p5AZp7r_Q

Scott, R. Blade Runner. Warner Bros, 1982.

Sega. Binary Domain. Sega 2012.

Shaw, A. "Do You Identify as a Gamer? Gender, Race, Sexuality, and Gamer Identity.” New Media \& Society 14, no. 1(2011): 28-44.

The Chinese Room. Dear Esther. The Chinese Room, 2012.

Tomas, D. “The Technophilic Body: On Technicity in William Gibson’s Cyborg Culture.” New Formations 8, Summer, 1989: 113-29.

Turkle, S. The Second Self: Computers and the Human Spirit. 20th Anniversary Ed. Cambridge: MIT Press, 2005.

Ubisoft Montreal. Assassin’s Creed. Ubisoft, 2007.

Wajcman, J. Feminism Confronts Technology. Pennsylvania: Pennsylvania State University Press, 1991.

Walker, A. "Me, On The Screen: Race in Animal Crossing: New Leaf." Clockwork Worlds, June 17, 2013. http://clockworkworlds.com/post/ 53240010750/me- on-the-screen-race-in 